\title{
Otimização do uso dos descritores morfo-agronômicos de mandioca em análise multivariada ${ }^{1}$
}

\author{
Optimizing the use of morpho-agronomic descriptors of cassava in multivariate \\ analysis
}

\author{
Jhonata Maia Vendramini², Leonarda Grillo Neves ${ }^{3 *}$, Marco Antonio Aparecido Barelli ${ }^{3}$, Júlio César Ferreira \\ Elias ${ }^{2}$ e Petterson Baptista da Luz
}

\begin{abstract}
Resumo - O presente trabalho tem por finalidade avaliar e caracterizar os acessos de mandioca que estão introduzidos na coleção de germoplasma da UNEMAT presentes no campo experimental da EMPAER do município de Cáceres, e verificar a utilização do uso dos descritores morfo-agronômicos quanto à sua eficiência, com emprego de variáveis multicategóricas, através de análise multivariada. Em cada acesso foram analisados e avaliados 40 descritores morfológicos e agronômicos, considerados como essenciais para a execução dos ensaios de distinguibilidade, homogeneidade e estabilidade dos acessos de Manihot ssp. O estudo demonstrou que com a exclusão do grupo dos descritores Mínimos obteve resultados de aproximadamente $92 \%$ de similaridade se comparados com o uso de todos os Descritores. Os resultados obtidos nos 38 acessos de mandioca do banco de germoplasma da UNEMAT campus Cáceres evidenciam existência de variabilidade genética.
\end{abstract}

Palavras-chave - Diversidade Genética. Manihot esculenta. Genética Vegetal.

\begin{abstract}
This paper aims to evaluate and characterize the cassava accessions that are being introduced into the germplasm collection of UNEMAT present in the experimental field EMPAER at the city of Cáceres, Mato Grosso, Brazil. It was also analyzed the use of morpho-agronomic descriptors as its efficiency with the use of multicategory variables through multivariate analysis. In each accession were analyzed and assessed 40 morphological and agronomic traits, which are considered essential to the tests for distinctness, uniformity and stability of Manihot accessions ssp. The study showed that excluding the group of least descriptors obtained results from about $92 \%$ similarity compared with the use of all words. Results obtained from 38 accessions of cassava germplasm bank of UNEMAT Caceres campus, show genetic variability.
\end{abstract}

Key words - Genetic Diversity. Manihot esculenta. Plant genetics.

\footnotetext{
*Autor para correspondência

${ }^{1}$ Recebido para publicação em 06/07/2010; aprovado em 05/05/2011

Pesquisa financiada pela FAPEMAT

${ }^{2}$ Curso de Agronomia do Campus Universitário de Cáceres/UNEMAT-MT, Brasil, jhonatamaia@hotmail.com, jcfe agro@hotmail.com

${ }_{3}^{3}$ Departamento de Agronomia do Campus Universitário de Cáceres/UNEMAT-MT, Brasil, leonardaneves@unemat.br, marcobarelli@terra.com.br, petterbaptista@yahoo.com.br
} 


\section{Introdução}

A mandioca (Manihot esculenta Crantz) é uma planta heliófila, perene, arbustiva, pertencente à família das Euforbiáceas. Nessa família são encontrados 290 gêneros e aproximadamente 7.500 espécies distribuídas por toda zona tropical do globo terrestre (ALVES et al., 2006), esta tem sua origem na America do Sul, onde é cultivada desde a Antigüidade pelos povos nativos deste continente. Cerca de 80 países produzem mandioca, caracterizando como a base de alimentação para grande parte da população, sendo que o Brasil é responsável por mais de $15 \%$ da produção mundial (AMARAL et al., 2007).

Estima-se que cerca de 700 milhões de pessoas no mundo tem a mandioca como principal fonte alimentar, sendo o Brasil, o principal consumidor de seu produto, a farinha. O consumo per capita de mandioca, no país, é da ordem de $70 \mathrm{~kg} \mathrm{ano}^{-1}$. A farinha é consumida em todo o território nacional, especialmente pela população de baixa renda. Atualmente, cerca de $85 \%$ da produção de mandioca são destinados à fabricação de farinha e amido e o restante vai para consumo in natura (raízes frescas) e indústrias de congelados e alimentação animal (ARCHANGELO et al., 2007).

Para a caracterização de genótipos de mandioca silvestre faz-se necessário quantificar e avaliar as variáveis quantitativas e qualitativas, sendo que o uso de técnicas multivariadas é um dos fatores que faz aumentar os estudos sobre diversidade genética entre os genótipos (LEDO et al., 2008). Cruz (2009) apresenta os procedimentos para estimar medidas de dissimilaridade com base em variáveis quantitativas, binárias e multicategóricas. Após as estimativas das distancias são submetidos a métodos de agrupamento. Estes têm por finalidade separar um grupo original de observações em vários subgrupos, de forma a obter homogeneidade dentro e heterogeneidade entre os subgrupos, destacando-se os hierárquicos e os de otimização que vem sendo empregado em grande escala pelos melhorista de plantas (BERTAN et al., 2006).

Nos métodos hierárquicos, os genótipos são agrupados por um processo que se repete em vários níveis, sendo estabelecido um dendograma, sem preocupação com o número ótimo de grupos. Destes, o método de distância média entre grupos (UPGMA) é o método mais simples para a construção de árvores filogenéticas, utilizando a média das distâncias entre todos os pares de genótipos para formação de cada grupo (CRUZ; CARNEIRO, 2003).

Normalmente, os dados qualitativos utilizados nas análisesmultivariadassãodenaturezabinária,istoé, ausência (0) ou presença (1) de uma determinada característica, porém para a caracterização morfo-agronômica são mais utilizadas as variáveis multicategóricas, com mais de duas classes por variável. Uma técnica que permite a análise simultânea de dados quantitativos e qualitativos foi proposta por Gower (1971). Este método permite que valores da matriz de distância fiquem compreendidos entre 0 e 1, sendo necessário a padronização das variáveis quantitativas e qualitativas (LEDO et al., 2008).

O presente trabalho tem por finalidade a avaliação e caracterização de acessos de mandioca que estão introduzidos na coleção de germoplasma da UNEMAT, e a otimização do uso dos descritores morfo-agronômicos, com emprego de variáveis multicategóricas.

\section{Material e métodos}

O presente trabalho foi realizado na Empresa Matogrossense de Pesquisa, Assistência e Extensão Rural (EMPAER) do município de Cáceres - MT com as seguintes coordenadas geográficas: $16^{\circ} 43^{\prime} 42^{\prime}$ ', de latitude Sul e 57 40' $51^{\prime}$, de longitude Oeste, a 118 metros de altitude, localizada às margens da BR $070 \mathrm{a}$ aproximadamente $12 \mathrm{~km}$ da mesma cidade onde está sendo mantida a coleção de acessos de mandioca da UNEMAT. A região apresenta clima tropical úmido, com temperatura média de $27,15^{\circ} \mathrm{C}$, e a pluviosidade anual varia de 1.100 a $1.200 \mathrm{~mm}$, concentrando $45 \%$ nos meses de dezembro a fevereiro (FIBGE, 2006).

Em cada acesso foram analisados e avaliados 40 descritores morfológicos e agronômicos, considerados como essenciais para a execução dos ensaios de distinguibilidade, homogeneidade e estabilidade dos acessos de Manihot ssp. que dividiram-se em quantitativos e qualitativos. Foram avaliados 38 acessos de mandioca do banco de germoplasma da UNEMAT (Universidade do Estado de Mato Grosso) de Cáceres - MT oriundos das cidades de Cáceres e Rosário Oeste situadas na região sudoeste de Mato Grosso, sendo eles: Branca (1), Sinop (2), Liberata (3), Espeto (4), Liberatão (5), Liberata (6), Cacau (7), Ligeirinho (8), Vermelha (9), Branquinha 12 (10), Seringueira (11), Liberata (12), Guaporé Vermelha (13), Amarelinha (14), Roxa (15), Vassourinha (16), Vermelha 18 (17), Faz. São Pedro (18), Aipim (19), Rondônia (20), Cacau Branca (21), Branquinha 26 (22), Não Identificado 1 (23), Não Identificado 2 (24), Aipim Cáceres (25), Branquinha (26), Pretinha 1 (27), Pretinha 2 (28), Cacau (29), Não Identificada 1 (30), Não Identificada 2 (31), Petterson (32), Cacau Vermelha (33), Cacau 2 Anos (34), Juriti (35), Seringueiro 2 (36), Cacau 8 mês (37), Branquinha 3 mês (38).

A caracterização morfo-agronômica dos genótipos foi realizada conforme escala proposta por Fukuda e Guevara (1998), tendo sido avaliadas tanto características de parte aérea quanto subterrânea (raízes tuberosas) das plantas. Em função do grande número de descritores 
propostos até então, identificou-se também a necessidade de classificá-los por categoria ou por ordem de importância. Ficou estabelecido, portanto, que os acessos de mandioca deveriam ser caracterizados de forma padronizada, mediante o uso de setenta e cinco descritores morfológicos e agronômicos. No presente trabalho foram avaliados treze descritores mínimos, doze principais, nove secundários e seis descritores agronômicos preliminares. Os descritores seguem com a numeração adotada pelo livro proposto por Fukuda e Guevara (1998).

Descritores Mínimos: 01. Cor da folha apical, 02. Pubescência do broto apical, 03. Forma do lóbulo central, 04. Cor do pecíolo, 05. Cor do córtex do caule, 06. Cor externa do caule, 07. Comprimento da filotaxia, 08. Presença de pedúnculo nas raízes, 09. Cor externa da raiz, 10. Cor do córtex de raiz, 11. Cor da polpa da raiz, 12. Textura da epiderme da raiz, 13 Floração.

Descritores Principais: 14. Cor da folha desenvolvida, 15. Número de lóbulos, 16. Comprimento do lóbulo, 17. Largura do lóbulo, 18. Relação comprimento/ largura do lóbulo central, 19. Comprimento do pecíolo, 20. Cor da epiderme do caule, 21. Hábito de crescimento de caule, 22. Cor dos ramos terminais nas plantas adultas, 23. Altura da planta, 24. Altura da primeira ramificação, 26. Constrições da raiz.

Descritores Secundários: 27. Cor da nervura, 28. Posição do pecíolo, 29. Proeminência das cicatrizes foliares, 30. Comprimento das estípulas, 31. Margem das estípulas, 32. Hábito de ramificação, 35. Sinuosidade do lóbulo foliar, 36. Forma da raiz, 37. Tipo de planta.

Descritores Agronômicos Preliminares: 42. Comprimento médio da raiz, 43. Diâmetro médio da raiz, 44. Destaque da película da raiz, 45. Destaque do córtex da raiz, 46. Posição das raízes, 47. Número de raízes por planta.

Os dados coletados foram avaliados utilizando a metodologia de variáveis multicategóricas, segundo Cruz e Carneiro (2003), através da equação 1.

$\mathrm{d}_{\mathrm{ii}}=\frac{\mathrm{D}}{\mathrm{C}+\mathrm{D}}$

Em que: $\mathrm{d}_{\mathrm{ii}}$ : dissimilaridade considerando um conjunto de variáveis multicategóricas; D: concordância de categoria; $\mathrm{C}$ : discordância de categoria.

Foi utilizado o Índice de Transformação Inverso 1-c, que visa contornar os possíveis problemas de indeterminação provocados nas condições em que o coeficiente assume valor " 0 ".

Para o método de UPGMA (Método de Agrupamento Médio Entre Grupos), o dendograma foi estabelecido pelos acessos com maior similaridade. Configura-se como um método não-ponderado de agrupamento aos pares, utilizando médias aritméticas das medidas de dissimilaridade, que evita caracterizar a dissimilaridade por valores extremos (máximo ou mínimo) entre os acessos considerados. A distância entre dois grupos formados foi dada pela média do conjunto, cujos elementos são as distancias entre os pares de acessos (CRUZ; CARNEIRO, 2003).

Neste método, o dendograma foi estabelecido pelos acessos com maior similaridade, e a distância entre o acesso k e um grupo formado pelos acessos i e j é dada pela equação (2):

$d(i j) K=m$ édia $\{d i k ; d j k\}=\frac{d i k+d j k}{2}$

Ou seja, d(ij)k será dada pela média do conjunto das distâncias dos pares de acessos de mandioca (i e k) e (j e k). O trabalho utilizou-se do recurso computacional Genes, versão 2009 (CRUZ, 2009).

\section{Resultados e discussão}

Os resultados obtidos com o método Hierárquico de distância média entre grupos (UPGMA) dos acessos de mandioca do município de Cáceres e Rosário Oeste no estado de Mato Grosso evidenciaram a existência de variabilidade genética.

As figuras representadas neste trabalho foram submetidas a um corte de aproximadamente $95 \%$ podendo verificar a formação de grupos, onde foram alocados os pares de acessos com maior similaridade.

Na Figura 1 foi possível observar a presença de 3 grupos, sendo que o grupo 1 foi responsável por 28,94\% dos 38 acessos avaliados, o grupo 2 foi composto por 25 acessos $(65,70 \%)$ e o grupo 3 com apenas 2 acessos (5,26\%) , sendo eles, 12 (Liberata) e 21 (Cacau Branca). Por sua vez, os acessos 25 (Aipim Cáceres) e 21 (Cacau Branca) foram os que se mostraram mais divergentes, enquanto que a menor divergência foi apresentada pelos acessos 25 (Aipim Cáceres) e 29 (Cacau). Essas divergências podem ser notadas utilizando o método da distância de média entre grupos (UPGMA) a fim de detectar grupos mais divergentes na coleção, assim como Zuin et al. (2009), estudando divergência genética entre 43 acessos de mandioca no município de Cianorte - PR, utilizando 12 descritores morfo-agronômicos, por analise multivariada com o mesmo método de agrupamento, obteve como resultado formação de grupos semelhantes. 


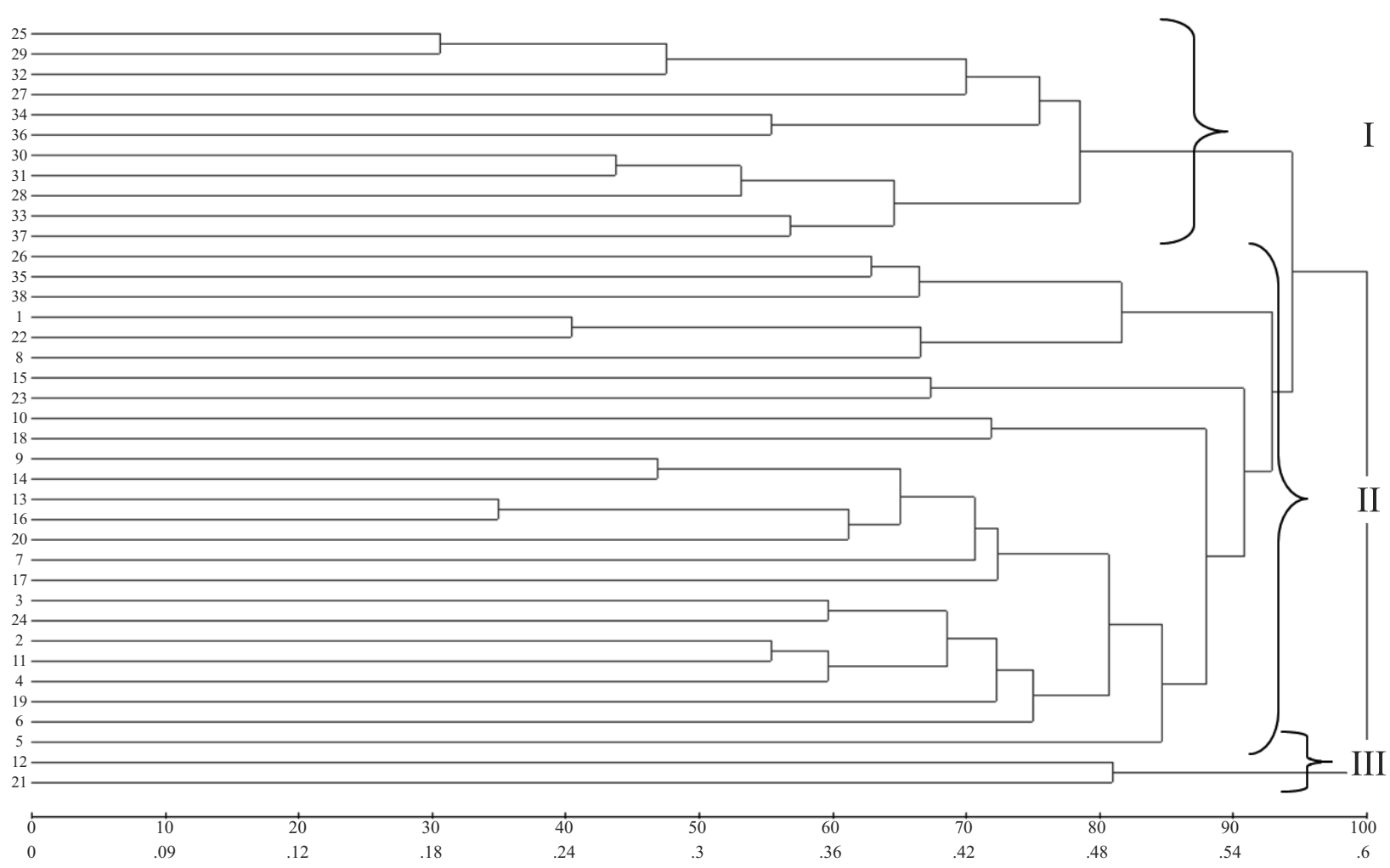

Figura 1 - Dendrograma ilustrativo do agrupamento entre os 38 acessos de mandioca (Manihot esculenta Crantz), obtido pelo Método de Agrupamento UPGMA, utilizando descritores morfo-agronômicos Totais

A Figura 2 é representada pelos descritores Principais, Agronômicos e Secundários. Está análise verificou que o grupo 1 possui $78,57 \%$ do acessos presentes similar ao grupo 1 da Figura 1, com um total de 11 acessos dos 14 que alocou neste grupo, o grupo 2 por sua vez obteve 2 acessos, com um total de $100 \%$ de similaridade ao mesmo grupo da Figura 1, já o grupo 3 foi o mais representativo com 22 acessos, sendo que, este grupo demonstrou ter $100 \%$ de similaridade com os acessos presentes no terceiro grupo dos descritores totais. Comparando os 3 grupos teremos um total de aproximadamente $92 \%$ de similaridade com a retirada dos descritores Mínimos, com isso apenas os acessos 26 (Branquinha), 35 (Juriti) e 38 (Branquinha 3 mês) estiveram alocados em grupos distintos aos da Figura 1. Entre os acessos que apresentaram ser mais próximos podemos destacar os 25 (Aipim Cáceres) e 29 (Cacau), e os mais divergentes 25 (Aipim Cáceres) e 21 (Cacau Branca).

A Figura 3 que é composta pelos descritores Principais, Mínimos e Secundários apresentou a formação de 3 grupos, onde pode-se notar que o grupo 1 foi formado por 10 acessos, com um total de $90 \%$ dos acessos similar ao grupo 1 da Figura 1, o grupo 2, foi composto por 26 acessos apresentando um total de $88 \%$ similar ao mesmo grupo da Figura 1, na formação do grupo 3 pode-se notar uma similaridade de $100 \%$ com os 2 acessos presentes neste grupo se comparados ao mesmo grupo da Figura 1. Com a saída dos descritores Agronômicos foi possível visualizar uma similaridade de aproximadamente $89 \%$. Os acessos com maior distância foram o 25 (Aipim Cáceres) e o 21 (Cacau Branca), enquanto que a menor divergência foi observada entre os acesso 25 (Aipim Cáceres) e 29 (Cacau). Esse resultado pode ser notado nos demais grupos de descritores com exceção de quando são retirados os descritores Principais dando resultados diferentes aos demais.

A Figura 4 que é composta pelos descritores Agronômicos, Mínimos e Secundários apresentou a formação de 3 grupos, sendo que o primeiro foi formado por 28 acessos, dos quais 16 aparecem com uma similaridade ao primeiro grupo da Figura 1, o segundo grupo foi composto por 9 acessos sendo que estes apresentaram $100 \%$ de similaridade, isso também é possível de visualizar na formação do grupo 3. Com a exclusão dos descritores Principais é possível obter uma similaridade de aproximadamente $69 \%$. Os acessos 25 (Aipim Cáceres) e 21 (Cacau Branca) foram os que apresentaram a maior distância, já os que apresentamse mais próximos foram os acessos 25 (Aipim Cáceres) e 29 (Cacau). 


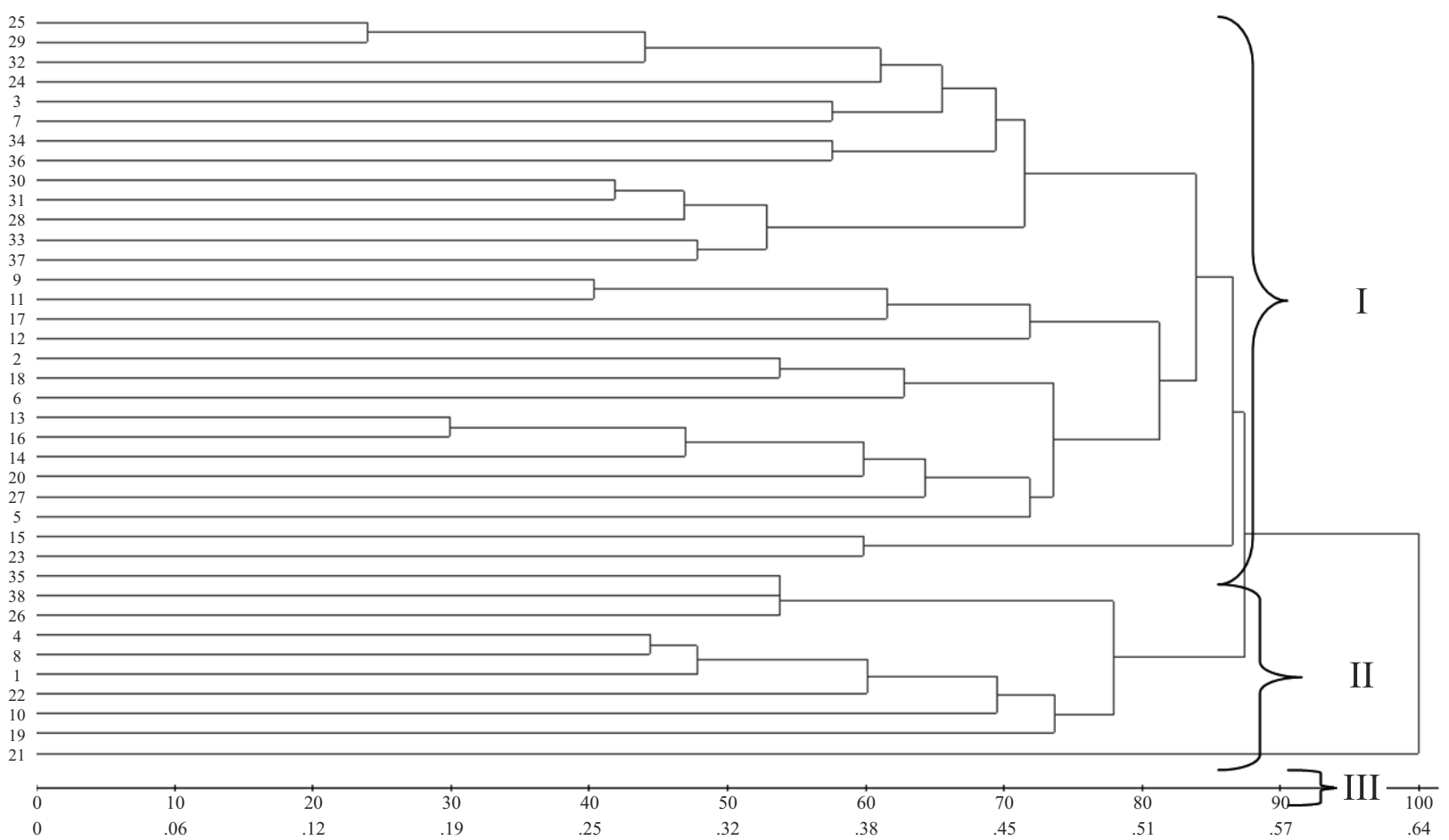

Figura 2 - Dendrograma ilustrativo do agrupamento entre os 38 acessos de mandioca (Manihot esculenta Crantz), obtido pelo Método de Agrupamento UPGMA, utilizando descritores morfo-agronômicos Principais, Secundários e Agronômicos

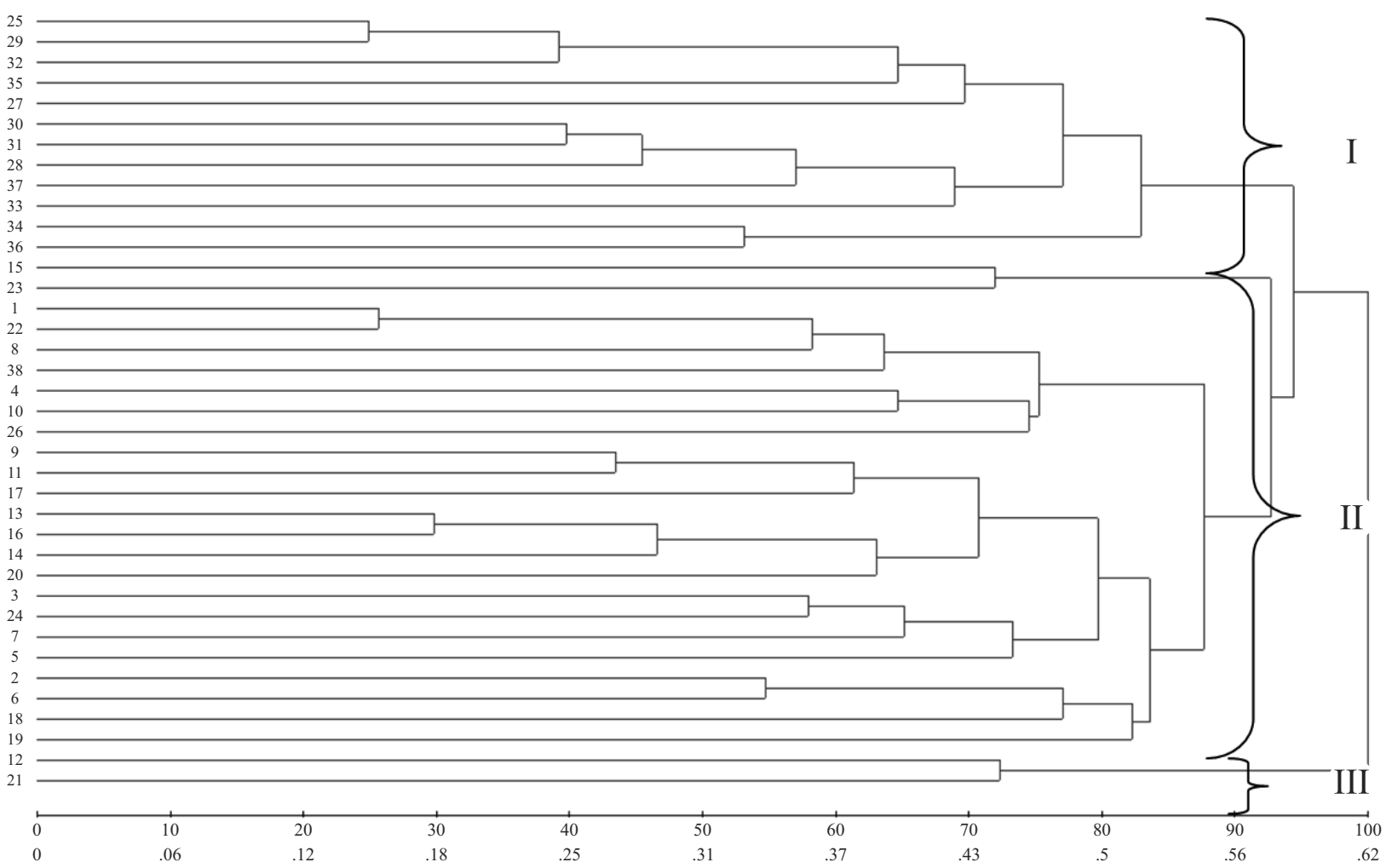

Figura 3 - Dendrograma ilustrativo do agrupamento entre os 38 acessos de mandioca (Manihot esculenta Crantz), obtido pelo Método de Agrupamento UPGMA, utilizando descritores morfo-agronômicos Principais, Mínimos e Secundários 


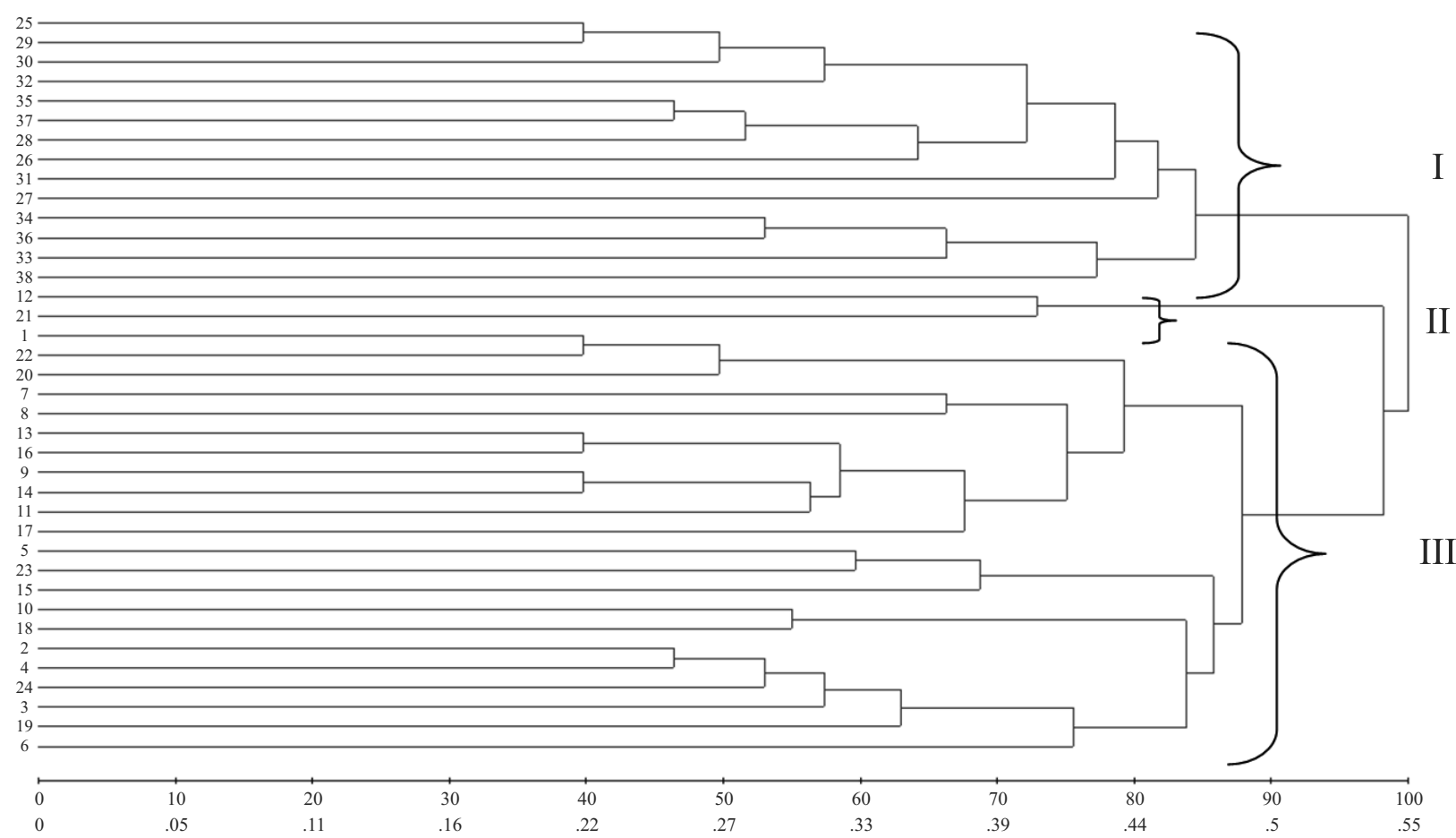

Figura 4 - Dendrograma ilustrativo do agrupamento entre os 38 acessos de mandioca (Manihot esculenta Crantz), obtido pelo Método de Agrupamento UPGMA, utilizando descritores morfo-agronômicos Secundários, Mínimos e Agronômicos

O agrupamento apresentado na Figura 5 é formado pelos descritores Mínimos, Agronômicos e Principais. Com formação de 3 grupos, pode-se notar que o primeiro grupo foi mais numeroso, composto de 35 acessos, dos quais 22 acessos apresentam similaridade com o grupo mais numeroso da Figura 1. O segundo grupo aparece com apenas um único individuo o acesso 5 (Liberatão). $\mathrm{O}$ terceiro grupo foi representado por 2 acessos, porém, tanto no segundo quanto no terceiro grupo não houve similaridade se comparados com os descritores Totais. De forma geral, este grupo de descritores apresentou cerca de $58 \%$ de similaridade comparados a todos descritores possíveis de serem analisados. Os acessos 30 (Não Identificada I) e 31 (Não Identificada II) foram os que se mostraram mais próximos.

Ométododemonstracerta semelhançano agrupamento dos acessos. O UPGMA oferece uma apresentação mais detalhada, podendo visualizar dentro dos grupos aqueles acessos com maior afinidade, possibilitando visualizar as distâncias dentro de um determinado grupo. Fato também observado por Kvitschal (2008), estudando a caracterização e divergência genética de germoplasma de Mandioca da região urbana de Maringá - PR. Bertan et al. (2006) relatam que o UPGMA discrimina cada acesso, possibilitando uma visão maior dentro de cada grupo e subgrupos.

Pode-se notar ainda que os acessos 3; 5 e 12 (Liberata), apesar de apresentar o mesmo nome comum, são materiais genéticos diferentes. Prova essa de que há variabilidade genética evidenciada pelo UPGMA. Silva et al. (2009) relata que na região de Cáceres há uma grande diversidade de etnovariedades, porém muitos acessos podem apresentar denominações iguais para meterias diferentes, pois a mandioca é uma espécie que apresenta grande variabilidade genética.

Observando os grupos I e II de cada agrupamento, pode-se notar que ambos apresentam a maioria dos acessos alocados, com algumas exceções, bem como apresentaram a formação de alguns grupos constituídos por apenas um único acesso, assim como pode-observar na Figura 4. De acordo com Vieira et al. (2005), grupos formados por apenas um indivíduo apontam na direção de que tais indivíduos sejam mais divergentes em relação aos demais. Esta semelhança na discriminação de genótipos pela divergência genética também é relatada por Martinello et al. (2001) e Martinello et al. (2003) em quiabeiro (Abelmoschus esculentus), por Silva et at. (2005) em feijão-de-vagem (Phaseolus vulgaris), e por Barelli et al. (2006) e Ceolin et al. (2007) em feijoeiro comum (Phaseolus vulgaris).

Sudré et al. (2006) caracterizaram a coleta de dados multicategóricos como sendo prática, econômica e com uma demanda menor de tempo, comparada a dados quantitativos e moleculares. Contudo, fazem uma 


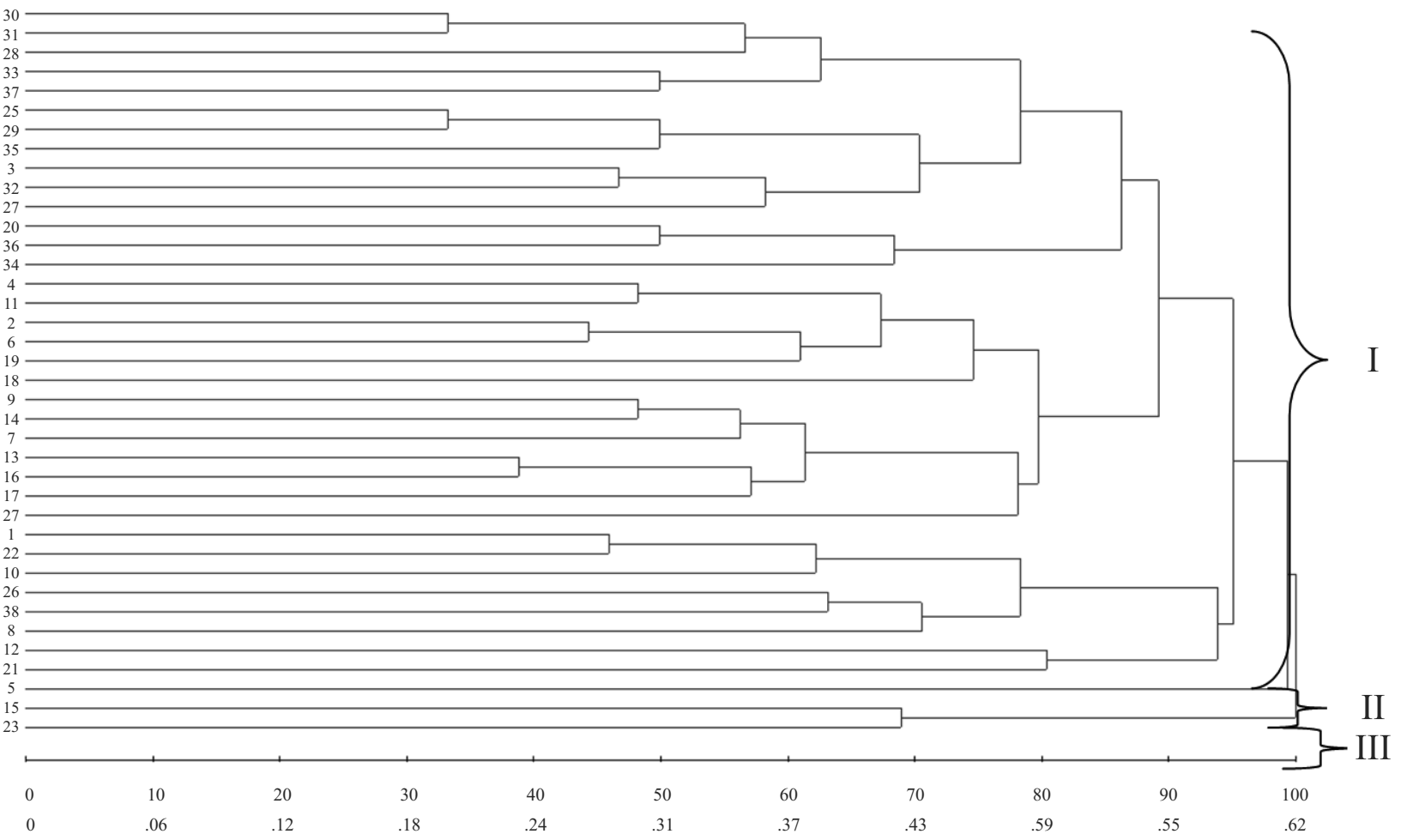

Figura 5 - Dendrograma ilustrativo do agrupamento entre os 38 acessos de mandioca (Manihot esculenta Crantz), obtido pelo Método de Agrupamento UPGMA, utilizando descritores morfo-agronômicos Agronômicos, Mínimos e Principais

ressalva de que cada um tem sua importância singular, sendo preferível que uma coleção de germoplasma seja amplamente estudada para que possa dar maior suporte aos programas de melhoramento.

O uso de todos os Descritores morfo-agronômicos é, sem dúvida, o que apresenta melhores resultados, porém, o presente trabalho demonstrou que com a exclusão do grupo dos descritores Mínimos obteve-se resultados de aproximadamente $92 \%$ de similaridade, tendo resultado de $100 \%$ em dois dos três grupos formados dentro do dendograma formado, sendo que, apenas 3 acessos presentes na coleção não foram similares. De forma geral, foram os descritores mais promissores, passíveis de serem explorados em programas de melhoramento genético na cultura da mandioca, usando os descritores morfo-agronômicos.

\section{Conclusões}

1. Os resultados obtidos nos 38 acessos de mandioca do banco de germoplasma da UNEMAT campus Cáceres, evidenciam variabilidade genética;

2. Verificou-se comprometimento do agrupamento ideal dos acessos quando retirado o grupo de descritores Principais e Secundários;
3. Há possibilidade de otimização do uso dos descritores morfo-agronômicos a partir da eliminação dos descritores Mínimos.

\section{Referências}

ALVES, J. M. A.; JAIGOBIND, A. G. A.; JAISINGH, S. Caracterização de dois clones de mandioca de mesa cultivados no cerrado de Boa Vista em Roraima. Revista Raízes e Amidos Tropicais, v. 03, 2007. Disponível em: $<$ http:www.cerat.unesp. br/volume3.php>. Acesso em: 10 maio 2010. AMARAL, L. et al. Processamento da mandioca. Curitiba: Instituto de tecnologia do Paraná, 2007. p. 48. (Dossiê Técnico).

ARCHANGELO, E. R. et al. Caracterização morfológica de acessos de mandioca nas condições edafoclimáticas de PalmasTO. Revista Raízes e Amidos Tropicais, v. 03, 2007. Disponível em: <http:www.cerat.unesp.br/volume3.php>. Acesso em: 10 maio 2010. BARELLI, M. A. A. et al. Genetic diversity among common bean (Phaseolus vulgaris L.) accessions based on RAPD markers. Annual report of the Bean Improvement Cooperative, v. 49, n. 01, p. 131-132, 2006.

BERTAN, I. et al. Comparação de métodos de agrupamento na representação da distância morfológica entre genótipos de trigo. Revista Brasileira Agrociência, Pelotas, v. 12, n. 03, p. 279-286, 2006. 
CEOLIN, A. C. G. et al. Genetic divergence of the common bean (Phaseolus vulgaris 1.) group 'Carioca'using morpho-agronomic traits by multivariate analysis. Hereditas, v. 144, n. 01, p. 1-9, 2007.

CRUZ, C. D. Programa Genes - Versão Windows: aplicativo computacional em genética e estatística. Viçosa: UFV, 2009.

CRUZ C. D; CARNEIRO P. C. S. Modelos biométricos aplicados ao melhoramento genético. Viçosa: UFV, 2003. 585 p.

FUNDAÇÃO INSTITUTO BRASILEIRO DE GEOGRAFIA E ESTATÍSTICA (FIBGE). Censo de 2006. Disponível em: $<\mathrm{http}: / / /$ www.sidra.ibge.gov.br/bda/agric/>. Acesso em: 16 nov. 2009.

FUKUDA, E. M. G.; GUEVARA, C. L. Descritores Morfológicos e Agronômicos para Caracterização de mandioca (Manihot esculenta, Crantz) Cruz das Almas: EMBRAPA - CNPMF, 1998. 38 p.

GOWER, J. C. A general coefficient of similarity and some of its properties. Biometrics, Arlington, v. 27, n. 04, p. 857-874. 1971.

KVITSCHAL, M. V. Caracterização e divergência genética de germoplasma de mandioca-de-mesa da região urbana de Maringá, Paraná. 2008. 88 f. Tese (Doutorado em Genética e Melhoramento). Universidade Estadual de Maringá, Maringá.

LEDO, A. S. et al. Avaliação de genótipos de bananeira na região do baixo São Francisco, Sergipe. Revista Brasileira. Fruticultura, v. 30, n. 03, p. 691-695, 2008.

MARTINELLO, G. E. et al. Divergência genética em acessos de quiabeiro com base em marcadores morfológicos. Horticultura Brasileira, Botucatu, v. 20, n. 01, p. 52-58, 2001.
MATINELLO, G. E. et al. Diversidade genética em quiabeiro baseada em marcadores RAPD. Horticultura Brasileira, Brasília, v. 21, n. 01, p. 20-25, 2003.

SILVA, H. B.; SEABRA JUNIOR, S.; BARELLI, M. A. A. Caracterização do sistema de cultivo de mandioca cultivados por produtores Urbanos e Peri - urbano de Cáceres. In: JORNADA CIENTIFICA DA UNEMAT, 2., 2009, Cáceres. Resumos... Cáceres, UNEMAT, 2009. p. 2.

SILVA, M. P. et al. Diversidade genética e identicação de híbridos por marcadores RAPD em feijão-de-vagem. Acta Scientiarum, v. 27, n. 03 , p. 531-539, 2005.

SUDRÉ, C. P. et al. Variáveis multicategóricas na determinação da divergência genética entre acessos de pimenta e pimentão. Horticultura Brasileira, v. 24, n. 01, p. 88-93, 2006.

VIEIRA, E. A. et al. Variabilidade genética para caracteres morfológicos entre acessos do banco de germoplasma de mandioca da Embrapa Cerrados. In: CONGRESSO BRASILEIRO DE MANDIOCA, 11., 2005, Campo Grande. Anais... Campo Grande, MS, 2005. 1 CD-ROM.

ZUIN, G. C. et al. Divergência genética entre acessos de mandioca-de-mesa coletados no município de Cianorte, região Noroeste do Estado do Paraná. Semina. Ciências Agrárias v. 30, n. 01, p. 21-30, 2009. 